\title{
Karla Armbruster
}

\section{Cross-Species Intimacies from Guide Dogs to Artificial Meat}

\section{Susan McHugh, Animal Stories: Narrating across Species Lines. Minneapolis: U of Minnesota $P, 2011.280$ pp. $\$ 25.00$ pb.}

On the cover of Susan McHugh's book, the subtitle "Narrating across Species Lines" bisects the title "Animal Stories" at a forty-five degree angle. This cover image astutely captures the general thrust of this work of criticism, which provides a number of new angles on literary and visual narratives featuring nonhuman animals - narratives ranging from genre fiction (Baynard Kendrick's mystery novels featuring a blind war veteran who works as a private investigator with his guide dog) to classic literature (George Orwell's Animal Farm) to film (Babe) to photography (Sue Coe's Dead Meat).

McHugh's central task is to explore when and how such narratives deconstruct the supremacy and inevitability of the humanist subject. She begins by challenging the assumption that nonhuman animals in these texts merely reflect human beliefs, fears, and desires. Joining recent work in science studies that reconceptualizes agency as more-than-human, she sets out to show the many ways that "other creatures become important not as supplements to human subject forms but rather as actors joining us in continuously shaping this one alongside a range of other narrative forms" (3). Thus, the questions she asks go beyond what types of relationships are represented between humans and other animals to how the texts affect and even enact intimacies between species.

The cross-species relationships that McHugh examines are organized into two parts. The first, "Intersubjective Fictions," explores narratives of two little-studied types of human-animal partnerships: blind detectives who work with guide dogs and female jump jockeys and their horses. While McHugh situates the development of these narratives in its cultural and historical context (down to the role that changing styles of women's underwear played in the evolution of professional riding by women and girls), her primary focus is, of course, the possibilities for intersubjectivity between humans and other animals. Disappointingly, she finds, moments of real, mutually constitutive partnership - such as the "complete-only-with-a-dog sense of self" (50) that can occur for humans who work with dogs in various capacities - are often overshadowed or undermined by a persistent focus on the achievements of human 
individuals (and this trend seems especially prevalent when the narratives are presented through film and television).

However, McHugh notes, fictions that "fram[e] food and sex as sites of entanglement ... elaborate how more generally human-animal relationships mutate into the worldly structures of non-human-centered agency" (4), and these mutations are the subject of the book's second part, "Intercorporeal Narratives." Noting the ways that modern petkeeping culture controls and limits the sexuality of pets, she finds challenges to this regime in the pet memoir - most prominently in the works of British writer J.R. Ackerley. McHugh's primary argument in this chapter elaborates the parallels between the difficulties posed for Ackerley's German shepherd Queenie (a.k.a. Tulip), a purebred who chooses to mate with a mongrel, and for homosexual men by the dominant "culture of breeders" (153). She is especially interested in situations where a third agent destabilizes culturally sanctioned couplings, creating a "sodomite culture" of multiplicity that acts as an alternative to "closed, interiorized selves with identities affixed in binary terms" (154). Her final chapter, on stories of meat animals and pigs in particular, charts the way that the industrialization of modern agriculture (including genetic engineering and artificial meat) has catalyzed works like Babe and Margaret Atwood's Oryx and Crake, which do not pit humans and animals against each other but show agribusiness as a "threat to whole ways of life shared across species" (202). As part of this analysis, McHugh finds some surprising examples of humans and animals intermingling in positive ways: Yes, most viewers anticipate and root for the happy barnyard community that emerges in Babe, but how many of us have viewed the genetically altered hybrids in Oryx and Crake as "extend[ing] the sense of barnyard as ongoing community relations"' (207)?

One of the most innovative aspects of McHugh's book is her interest in narrative forms and the ways they can "serve as spawning grounds for forms of species and social agency" (19). She begins by challenging the widely held view that the novel's success is due to its emphasis on the individual human subject, asserting instead that its rise as a genre grows from its "usefulness for experiments with multiple perspectives and processes that support models centered on agency rather than subjectivity" (1). She finds visual narrative forms especially useful for experimenting in this way, as when the giggling mice that periodically appear at the edges of the screen and read the cuecard-like intertitles in the film Babe provide a "figuration of multiplicity" (198), and she even explores visual elements within written texts, such as the opening scene of the novel National Velvet, in which the girl Velvet Brown plays with cut-out images of

Humanimalia: a journal of human/animal interface studies

Volume 4, Number 1 (Fall 2012) 
famous horses - in other words, uses visual media to imagine her potential sporting life with horses, as McHugh points out (79).

McHugh also provides a nicely even-handed examination of the role of technology in these narratives, pointing to not just the ways it has constrained the lives and interactions of humans and nonhumans alike, such as the role of television in eroding a sense of interspecies teamwork in National Velvet, but also the ways it can break open oppressive discursive structures, as when the televised sheep-herding trials in Babe help bring about a happy ending, "a cyborg vision of machine-human-animal integration that defies so much of the history of meat processing" (193).

As must be clear by now, McHugh's discussion of animal stories finds and follows nearly countless analytical trails to hunt down both the ways these narratives escape and even challenge humanist ideology as well as the ways they are limited by it. This wide-ranging inquiry gives the book great interest and energy, but it also means that at times the reader is given just a peek down a side-path before the journey continues in a different direction; in addition, the darting, exploratory nature of her writing style sometimes requires careful concentration to keep the main path of the argument in sight. For readers interested in truly original insights into twentieth-century animal narratives and their intersections with lives shared across species, though, these minor challenges are well worth it. 